\title{
Irrigation Requirement for Eucalyptus pellita during Initial Growth
}

\author{
Dwinata Aprialdi 1,2,*, Muhammad Ibnu Haiban ${ }^{1}$, Bjørn Kløve ${ }^{2}$ and Ali Torabi Haghighi ${ }^{2}$ \\ 1 Research and Development Department, PT. Arara Abadi, Sinarmas Forestry, Perawang, Riau 28685, \\ Indonesia; haiban1194@gmail.com \\ 2 Water, Energy and Environmental Engineering Research Unit, PO Box 4300, University of Oulu, 90014 \\ Oulu, Finland; Bjorn.klove@oulu.fi (B.K.); ali.torabihaghighi@oulu.fi (A.T.H.) \\ * Correspondence: dwinataaldi@gmail.com
}

Received: 14 August 2019; Accepted: 16 September 2019; Published: 21 September 2019

\begin{abstract}
The growth of Eucalyptus pellita in forestry plantations requires attention to water requirements, especially in the initial growth phase from seedling to field-ready plant. In this study, actual evapotranspiration $\left(\mathrm{ET}_{\mathrm{a}}\right)$, crop coefficient $\left(\mathrm{K}_{\mathrm{c}}\right)$, and the irrigation requirement of E. pellita were assessed during the nursery growth phase (day 40-142). The experimental set-up included lysimeters with different treatments in terms of plants, drainage, and soil conditions. Plant growth and water balance were monitored during June September 2018 in an open nursery area in Riau, Indonesia. $\mathrm{ET}_{\mathrm{a}}$ was determined by the water balance lysimeter method and potential (reference) evapotranspiration (ETo) was extracted based on the Penman-Monteith method (FAO/56). The results showed that the average $K_{c}$ value for E. pellita at age $40-142$ days is 0.79 , which exceeds that reported for $E$. grandis. The recommended irrigation requirement varies depending on precipitation, from $70 \mathrm{~mL} /$ plant/day with no rainfall to zero at precipitation of $>30 \mathrm{~mm} /$ day. This is the first study to assess water use in E. pellita growing in pots during the nursery phase, which provides guidance on irrigation requirements during their initial growth phase.
\end{abstract}

Keywords: evapotranspiration; forestry; tropical soils; crop growth; water balance; nursery plants

\section{Introduction}

Eucalyptus is a main forest crop in tropical and subtropical regions. In Southeast Asia, Eucalyptus is cultivated in, e.g., Papua New Guinea and Indonesia [1]. In recent decades, forestry plantation in Indonesia has become a large-scale industry producing timber and wood pulp on more than 5 million hectares. On mineral soils, these plantations are based on Eucalyptus pellita, as a source of pulp and paper products [2,3]. Eucalyptus pellita grows rapidly, with a straight stem, and has high tolerance to various soil types and high resistance to pests and diseases [4].

Despite its commercial importance, the water requirement for irrigating E. pellita is poorly known [5]. In Indonesia, the species typically faces water stress due to too much water (during rainy season, October-December, with $250 \mathrm{~mm}$ rainfall per month on average) or too little (during rainfree periods of up to several months). Eucalyptus pellita is susceptible to soil moisture stress due to its rapid growth, driven by high photosynthetic and transpiration rates [6]. Low soil water availability restricts plant growth, especially in seasonally dry regions.

Crop coefficient $\left(\mathrm{K}_{\mathrm{c}}\right)$, defined as the ratio of actual to potential evapotranspiration, plays an essential role in various agricultural practices and has been widely used to estimate actual crop evapotranspiration $\left(\mathrm{ET}_{\mathrm{a}}\right)$ in irrigation scheduling. The United Nations Food and Agriculture Organization (FAO) provides crop coefficient values for a large number of crops under different climate conditions, for use in places where local data are not available [7]. However, empirical crop coefficients have been criticized because their values may vary according to weather conditions and 
the crop stage in which they are derived. As an alternative, weighing lysimeters have been used to determine ETa by partitioning a simple water balance equation [8] that presents a procedure for evaluating the accuracy of $\mathrm{ET}_{\mathrm{a}}$ values obtained from measurements using large precision lysimeters. For measuring potential (reference) evapotranspiration (ETo), several methods are available, e.g., Penman-Monteith, Modified Penman, Makkink, Hargreaves, and evaporation pan.

In this study, the water needs of E. pellita were assessed in a controlled irrigation and growth experiment. The aim was to address possible errors in supplementary irrigation estimates for E. pellita grown in tropical environments, which could cause an increase in production costs and low crop yield. Our first objective was to determine $\mathrm{ET}_{\mathrm{a}}, \mathrm{K}_{\mathrm{c}}$, and the irrigation requirement of E. pellita grown in a tropical climate (Indonesia). The second objective was to analyze the relationship between evapotranspiration and other climate factors (e.g., precipitation, wind speed, humidity, solar radiation, etc.). Evaporation and percolation/leaching in the field were also compared. The overall intention was to provide guidance on production of E. pellita in nursery gardens.

\section{Material and Method}

\subsection{Experimental Site}

An irrigation and E. pellita growth experiment was carried out from June 2018 to September 2018 in an open nursery belonging to the Sinarmas Forestry plantation company, located in Perawang district, Riau province, Indonesia $\left(0^{\circ} 41^{\prime} 39^{\prime \prime} \mathrm{N} ; 1^{\circ} 01^{\circ} 36^{\prime} 21^{\prime \prime} \mathrm{E} ; 16 \mathrm{~m}\right.$ asl) (Figure 1). Mean annual rainfall in the area is $2244 \mathrm{~mm}$ and there is a dry season that generally starts in June and ends in September. Mean monthly rainfall is around $130 \mathrm{~mm}$ in the dry season and $220 \mathrm{~mm}$ in the rainy season. The age of E. pellita plants during the experiment ranged from 42 days to 142 days. An automatic weather system (AWS) was installed about $20 \mathrm{~m}$ from the study site, to record precipitation, temperature, relative humidity, and net radiation.

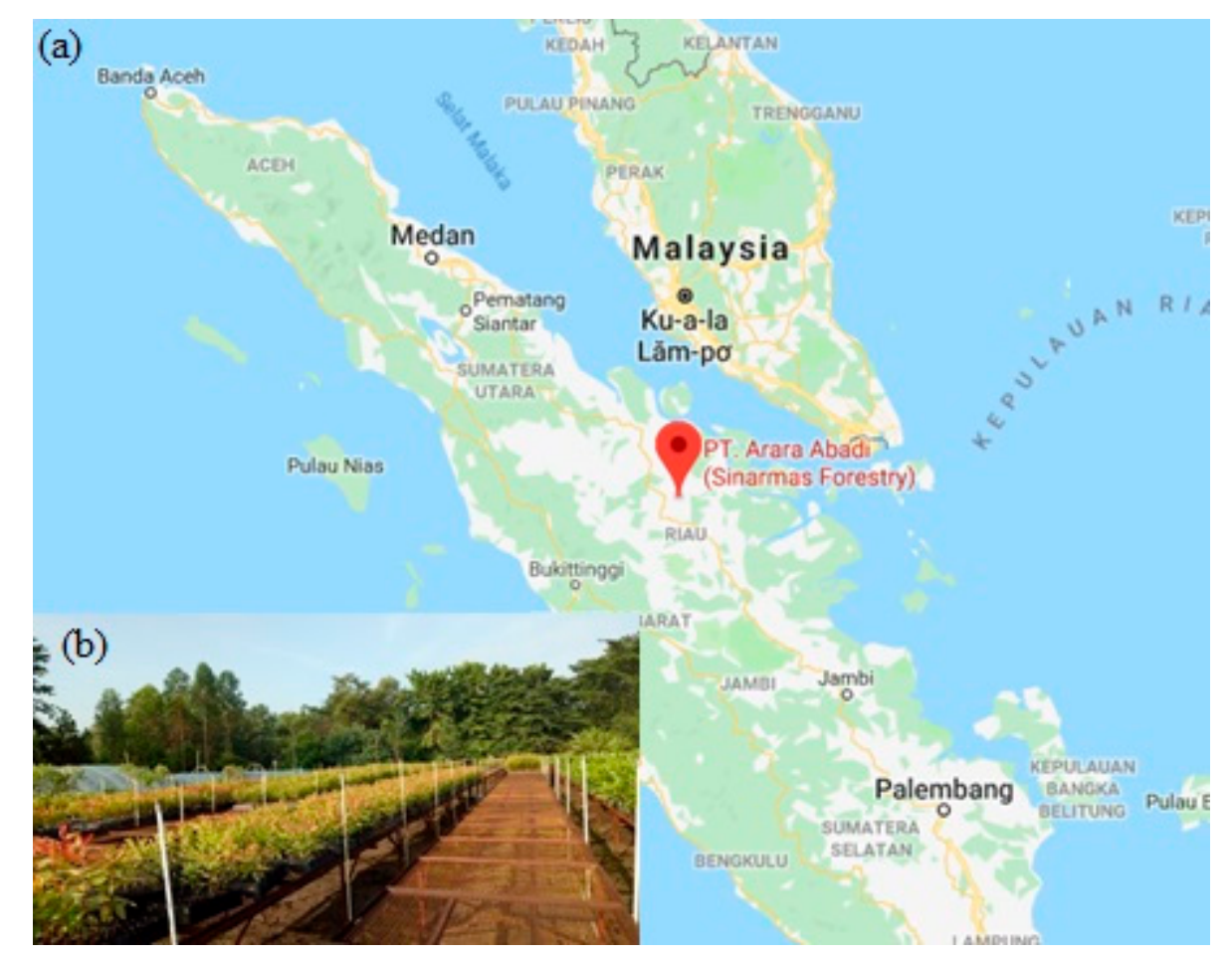

Figure 1. Location of the study site in Riau Province, Indonesia (a), and Eucalyptus pellita plants growing in open nursery beds (b). 


\subsection{Experimental Design}

The experimental set-up involved recording the water balance of individual plants growing in sets of 32 tubes of growing medium arranged in pottery pallets (Figure 2). Four different treatments were applied:

- $\quad$ Treatment 1 (T1): Plants + watering + free drainage

- $\quad$ Treatment 2 (T2): No plants + watering + free drainage

- Treatment 3 (T3): No plants and no watering + free drainage

- $\quad$ Treatment 4 (T4): No plants + watering and no drainage (tube bottom sealed).

Each tube was irrigated $(50 \mathrm{~mL})$ on two occasions per day: in the morning $(08.30 \mathrm{~h})$ and afternoon $(14.00 \mathrm{~h})$. Each treatment consists of 32 tubes that considered as repetition. The outflow from each tube was collected and measured, to monitor drainage (Figure 3a). The seedling density in the pallets and tube dimensions followed the forestry company standard (Figure 2b,d). Every plant was labeled in order to avoid confusion during the daily assessment (Figure 2a).

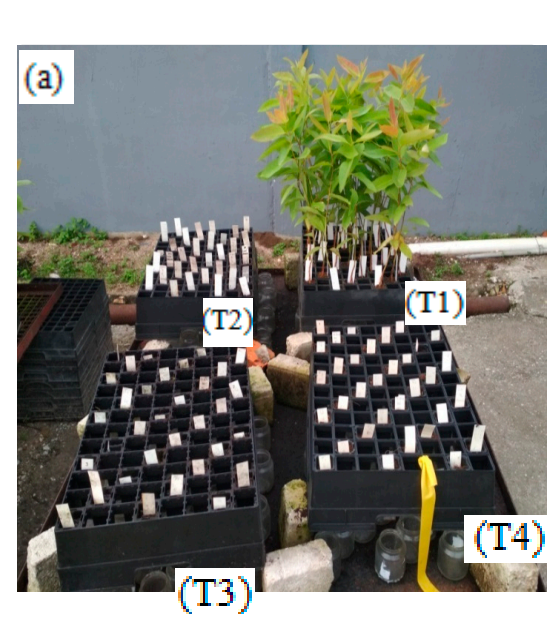

$33 \%$ Population/Pottery

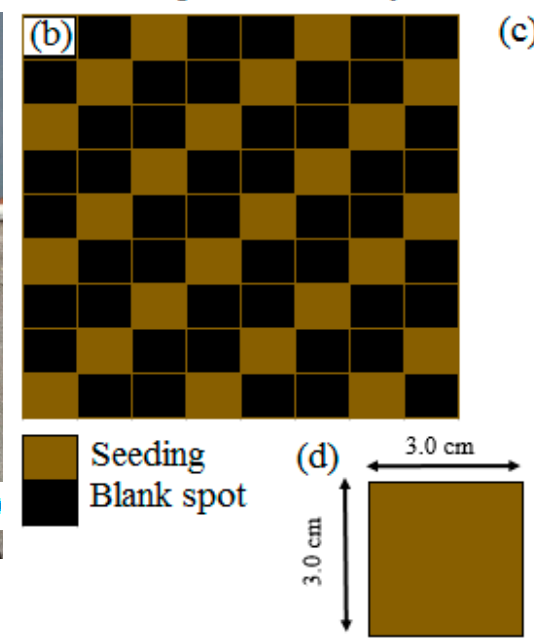

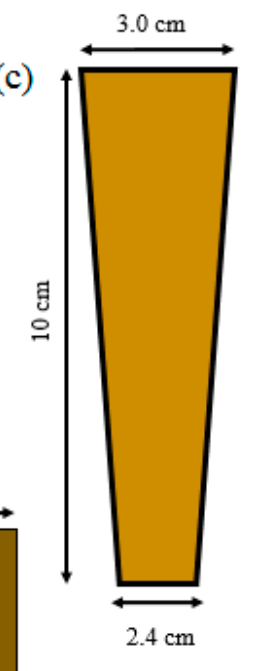

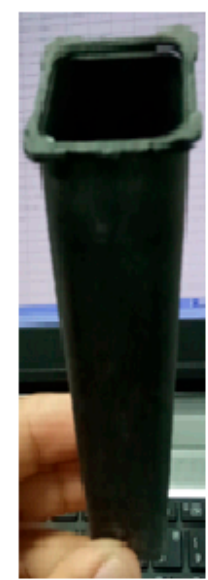

Figure 2. (a) Pottery pallets containing tubes of Eucalyptus pellita plants in treatments T1-T4, (b) layout of seedlings and blanks in treatment $\mathrm{T} 1$, and $(\mathbf{c}, \mathbf{d})$ side and top view of a tube and its dimensions.

The tubes, with dimensions of $3 \mathrm{~cm}$ by $3 \mathrm{~cm} \times 10 \mathrm{~cm}$ height (Figure $2 \mathrm{c}$ ), were filled with organic material (coco-peat $67 \%$, carbonized rice husk $33 \%$ ) by the machine. Data on daily air temperature, wind speed, solar radiation, and relative humidity used for estimating $E_{0}$ and daily rainfall data were collected from the AWS at the study site.

During the study period, daily measurements were conducted on weekdays to determine different components of the water balance in each tube. These measurements consisted of three steps: i) irrigation, ii) weighing the tube (to determine soil moisture), and iii) measuring the outflow (Figure 3). During weekends (Saturday and Sunday) and national holidays, the pallets were moved to a sprinkler irrigation area and no measurements were made. A soil moisture sensor (SM $150 \mathrm{~T}$ from Delta-T Devices) was used to measure the moisture content in the growing medium during the experiment. The sensor was calibrated before use according to the manufacturer's instructions, based on actual moisture measurements on 30 samples of growing medium. This yielded a linear relationship $\left(R^{2}=0.968\right)$ between the soil moisture value measured by the sensor and the actual soil moisture of samples:

$$
C_{S M}=0.36 \times M_{S M}+9.98
$$

where CSM is the calibrated value and Msм is the value measured by the sensor.

\subsection{Irrigation Demand and Crop Coefficient}


Crop coefficient is defined as the ratio of actual to potential evapotranspiration:

$$
\mathrm{K}_{\mathrm{c}}=\mathrm{ET}_{\mathrm{a}} / \mathrm{ET}_{\mathrm{o}}
$$

where $\mathrm{ET}_{\mathrm{o}}$ can be calculated based on the meteorological approach, while an experimental approach is recommended to estimate $\mathrm{ET}_{\mathrm{a}}$ [9].

According to Penman-Monteith model, ETo can be calculated using meteorological elements and incorporating parameters for crop resistance, albedo, and air resistance. In the present study, the value of ETo was extracted from the AWS data as:

$$
\text { ETo }=\frac{0.408 \Delta(\mathrm{Rn}-\mathrm{G})+\gamma \frac{900}{\mathrm{~T}+273} \mathrm{u}_{2}\left(\mathrm{e}_{\mathrm{s}}-\mathrm{e}_{\mathrm{a}}\right)}{\Delta+\gamma\left(1+0.34 \mathrm{u}_{2}\right)}
$$

where $\mathrm{ET}_{\mathrm{o}}$ is reference (potential) evapotranspiration $\left[\mathrm{mm} \mathrm{day}^{-1}\right], \mathrm{R}_{\mathrm{n}}$ is net radiation at the crop surface $\left[\mathrm{MJ} \mathrm{m}^{-2}\right.$ day $\left.^{-1}\right], \mathrm{G}$ is soil heat flux density [ $\mathrm{MJ} \mathrm{m}^{-2}$ day $\left.^{-1}\right], \mathrm{T}$ is mean daily air temperature at 2 $\mathrm{m}$ height $\left[{ }^{\circ} \mathrm{C}\right], \mathrm{u}_{2}$ is wind speed at $2 \mathrm{~m}$ height $\left[\mathrm{m} \mathrm{s}^{-1}\right]$, $\mathrm{e}_{s}$ is saturation vapor pressure [kPa], ea is actual vapor pressure $[\mathrm{kPa}], \Delta$ is slope vapor pressure curve $\left[\mathrm{kPa}{ }^{\circ} \mathrm{C}^{-1}\right]$, and $\gamma$ is a psychometric constant $\left[\mathrm{kPa}{ }^{\circ} \mathrm{C}^{-1}\right]$.

An experimental method (Figure 3) was used to calculate ETa in treatment T1. Lysimeters provided weight-based estimates of $\mathrm{ET}_{\mathrm{a}}$ and percolation were used to observe crop growth, as recommended by [10]. The water balance was then calculated using the data obtained as:

$$
\mathrm{R}+\mathrm{I}=\mathrm{ET}_{\mathrm{a}}+\mathrm{DS}+\mathrm{P}
$$

where $\mathrm{R}$ is rainfall, I is irrigation, $\mathrm{ET}_{\mathrm{a}}$ is actual evapotranspiration by the crop, DS is the change in soil water storage following addition of water, and $\mathrm{P}$ is drainage, all in $\mathrm{mm}$.

In treatments T2-T4, where there were no plants present, actual evaporation (Ea) was calculated instead of ETa:

$$
\mathrm{R}+\mathrm{I}=\mathrm{Ea}+\mathrm{DS}+\mathrm{P}
$$

For treatment T4, where drainage from the system was not permitted, some of the irrigation water applied overflowed the tubes. There were no facilities for measuring this overflow, thus, estimating the exact amount of evaporation was impossible. Therefore, for treatment $\mathrm{T} 4$, the equation was modified to:

$$
\mathrm{R}+\mathrm{I}=\left(\mathrm{E}_{\mathrm{a}}+\mathrm{S}_{\mathrm{p}}\right)+\mathrm{DS}+(\mathrm{P}=0)
$$

where $S_{p}$ is overflow from the tube. 


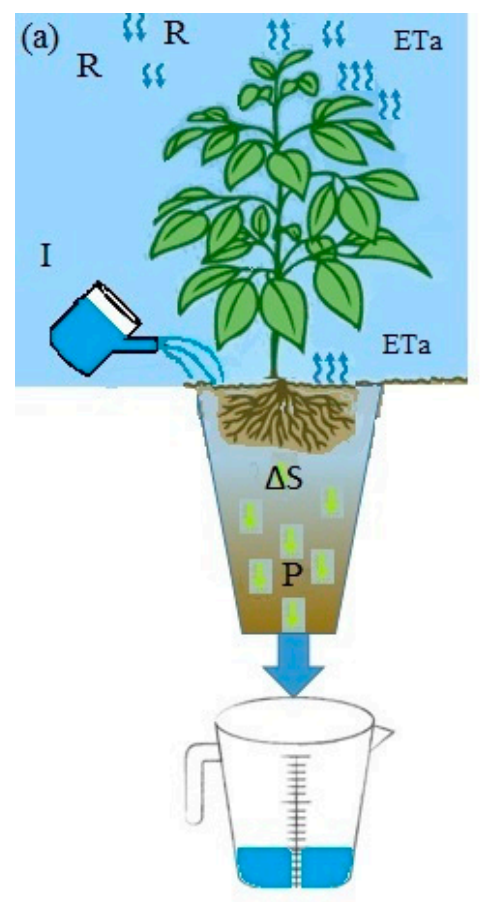

(b)

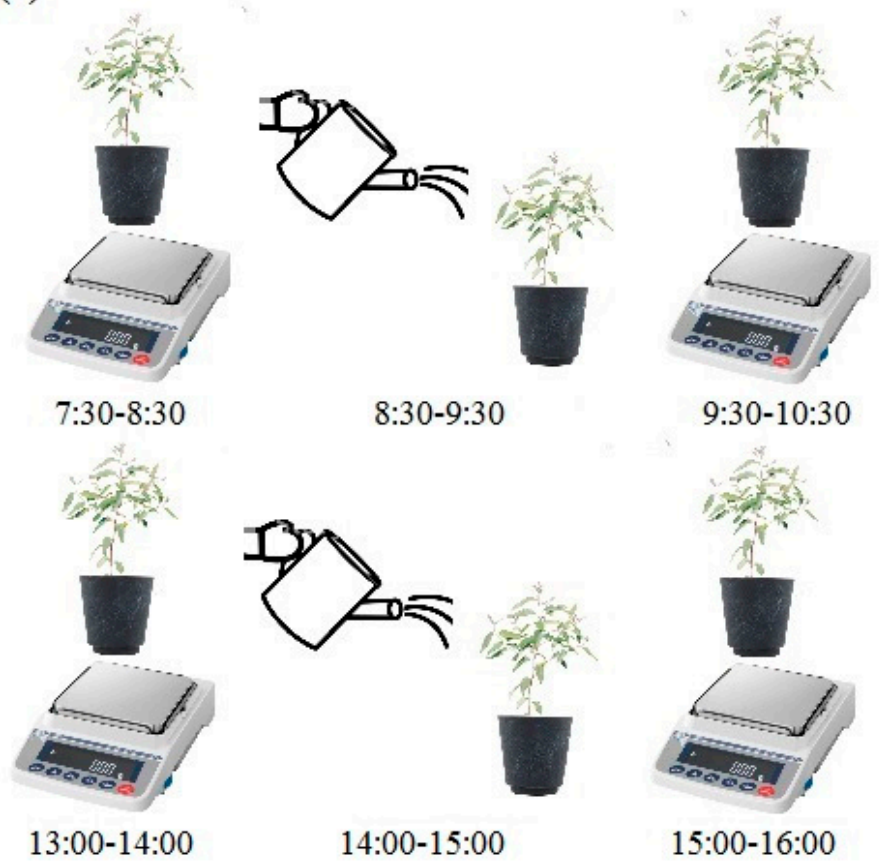

Figure 3. (a) Water balance components in lysimeter measurements of actual evapotranspiration $\left(E T_{a}\right)$, where $\mathrm{R}$ is rainfall, $\mathrm{P}$ is percolation, and $\mathrm{I}$ is irrigation, and (b) daily measurement and irrigation schedule in the experiment.

The experimental set-up allowed $E T_{a}$ to be measured in the morning and afternoon. Daily $E T_{a}$ was then taken as the combined morning and afternoon values. The change in soil water storage $(\Delta S)$ brought about by addition of water was determined as:

$$
\mathrm{DS}=\mathrm{S}_{\mathrm{t}}-\mathrm{S}_{\mathrm{t}-1}
$$

where $S_{t}$ and $S_{t-1}$ are soil water storage at time $t$ (after watering) and $t-1$ (before watering). These values were determined by measuring soil moisture content (by sensor) and considering the soil layers from the surface $(z=0)$ to the bottom of the tubes $(z=0.1 \mathrm{~m})$.

\section{Result and Discussion}

\subsection{Comparison of Water Balance Components in Different Treatments}

The total amount of water applied to the plants in treatment T1 was $2756 \mathrm{~mm}$, which comprised $2651 \mathrm{~mm}$ as irrigation water and $105 \mathrm{~mm}$ as rainfall (Figure 4(b1)). The measured outflow was 1962 $\mathrm{mm}$, which was considered as drainage (or percolation). The difference between water added and percolation, which was assumed to represent $E T_{a}$, was $380 \mathrm{~mm}$. The change in soil water storage $(\Delta S)$ following addition of water was on average $414 \mathrm{~mm}$. Total cumulative soil $\mathrm{E}_{\text {a }}$ (actual evaporation) was estimated from treatment T2, in which there were no plants (Figure 4(d2)), and was found to be $305 \mathrm{~mm}$, i.e., around half the value of $E T_{a}$ in treatment $\mathrm{T} 1$.

Total cumulative soil $E_{a}$ in non-irrigated conditions was estimated from treatment T3 (no plants, no irrigation, free drainage) and was found to be $151 \mathrm{~mm}$, i.e., around half the value in irrigated conditions (T2) and one-fifth of $E T_{a}$ in T1. As mentioned, the amount of $E_{a}$ in treatment T4 included overflow from the tubes (Figure 4(d4)). Among the three treatments involving irrigation (T1, T2 and $\mathrm{T} 4)$, the lowest variation in soil moisture content was observed in $\mathrm{T} 4$, because there was no drainage system and the total amount of water applied (2756) mm greatly exceeded actual soil $E_{a}(305 \mathrm{~mm})$. Therefore, the soil in $\mathrm{T} 4$ was almost at saturation at all times (before and after irrigation). 


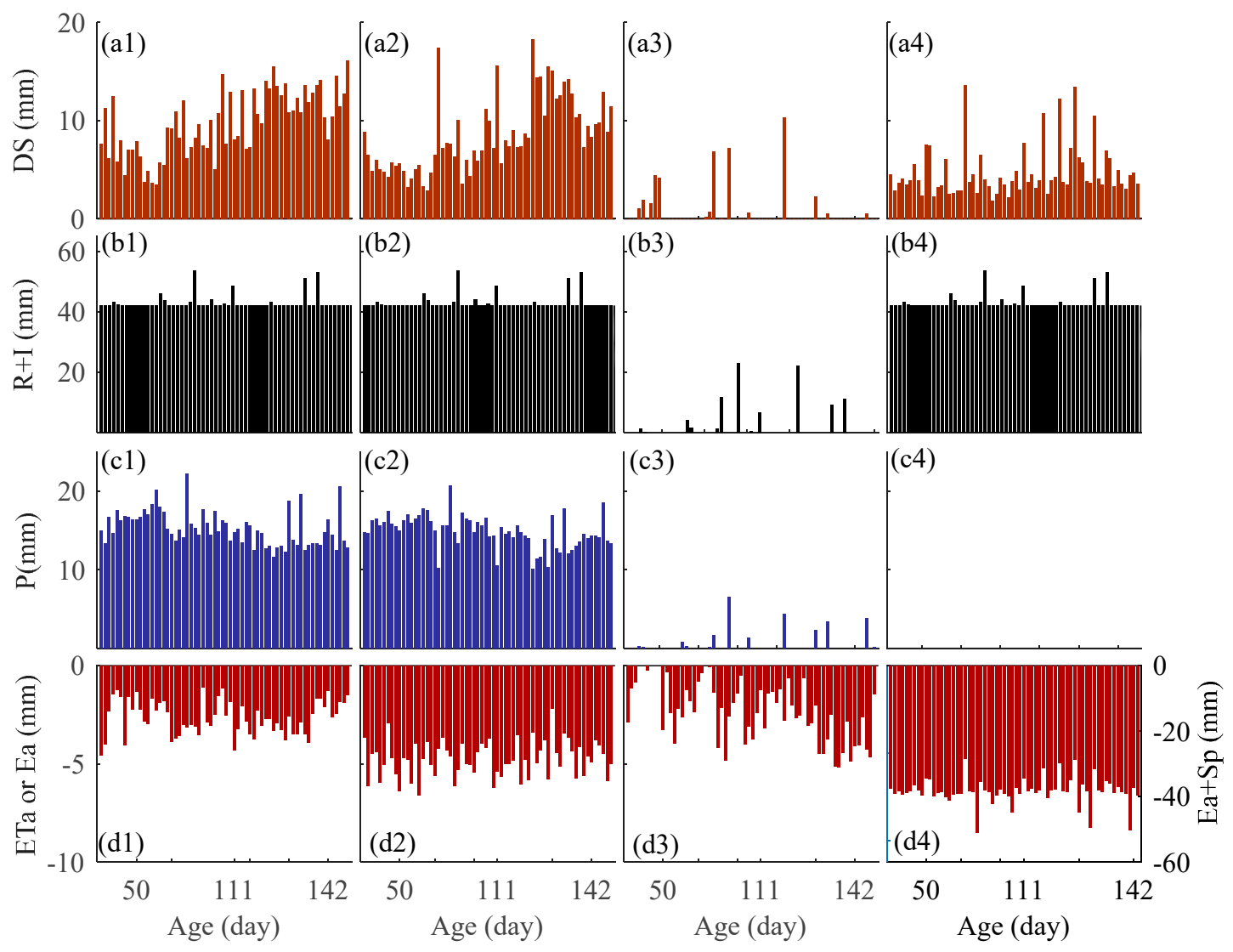

Figure 4. Water balance components in the different treatments (where 1-4 represent T1-T4, respectively) from $07: 30 \mathrm{~h}$ to 16:00 $\mathrm{h}$ on day 40-142 of Eucalyptus pellita growth: (a1-a4) change in soil water storage (DS), (b1-b4) rainfall (R) plus irrigation (I), (c1-c4) percolation (P) and (d1-d4) evapotranspiration $\left(\mathrm{ET}_{\mathrm{a}}\right)$ or evaporation $\left(\mathrm{E}_{\mathrm{a}}\right)$.

\subsection{Soil Moisture Variations}

Soil moisture (SM) was measured during irrigation periods (DIP; 08:00 h-16:00 h) (Figure 5(a1d1)) and outside irrigation periods (OIP; 16:00 h-08:00 h) (Figure 5a2-d2). The OIP soil moisture content decreased (showed negative values) in all treatments (T1-T4) except during rainfall events (Figure 5(a2-d2)). In the treatments where irrigation was applied (T1, T2 and T4), DIP increased accordingly (positive values), but some negative values were recorded (Figure 5(a1-d1)). These occurred when the decrease in soil moisture content in the afternoon between the two watering exceeded the increase in soil moisture after the second watering.

It must be pointed that the sensor was used to measure the moisture in the growing medium four times per day over 64 days of measurement, giving a total of 256 measurements. Based on soil moisture characteristic tests in the laboratory, the wilting point ( $\mathrm{pF} 4.2$ ) of the growth medium was determined to be $18 \%$-vol., field capacity ( $\mathrm{pF} 2$ ) was $27.5 \%$-vol., and the saturation point ( $\mathrm{pF} 1$ ) was $47.3 \%$-vol.

In the irrigated treatments (T1, T2, and T4), the change in soil moisture over time was more affected by irrigation than rainfall (irrigation volume was $42 \mathrm{~mm}$ /day). Soil moisture content was always above wilting point and below saturation point, either before or after irrigation. The greatest fluctuation in soil moisture content was observed in treatment $\mathrm{T} 2$, where there were no plants and therefore no water loss, and the smallest fluctuation was in T4, where the soil was always near saturation and there were no drainage losses of the irrigated water applied. Treatment T3 (no irrigation) represented natural conditions in the field, because the only water source for the plants was rainfall. The greatest increase in soil moisture in T3 was from 19\%-vol. to 39\%-vol., which was brought about by a rainfall event supplying $23 \mathrm{~mm}$ in one day. This indicates that irrigation of $E$. 
pellita plants is urgently needed during the dry season in order to ensure that there is no water deficient restricting growth.
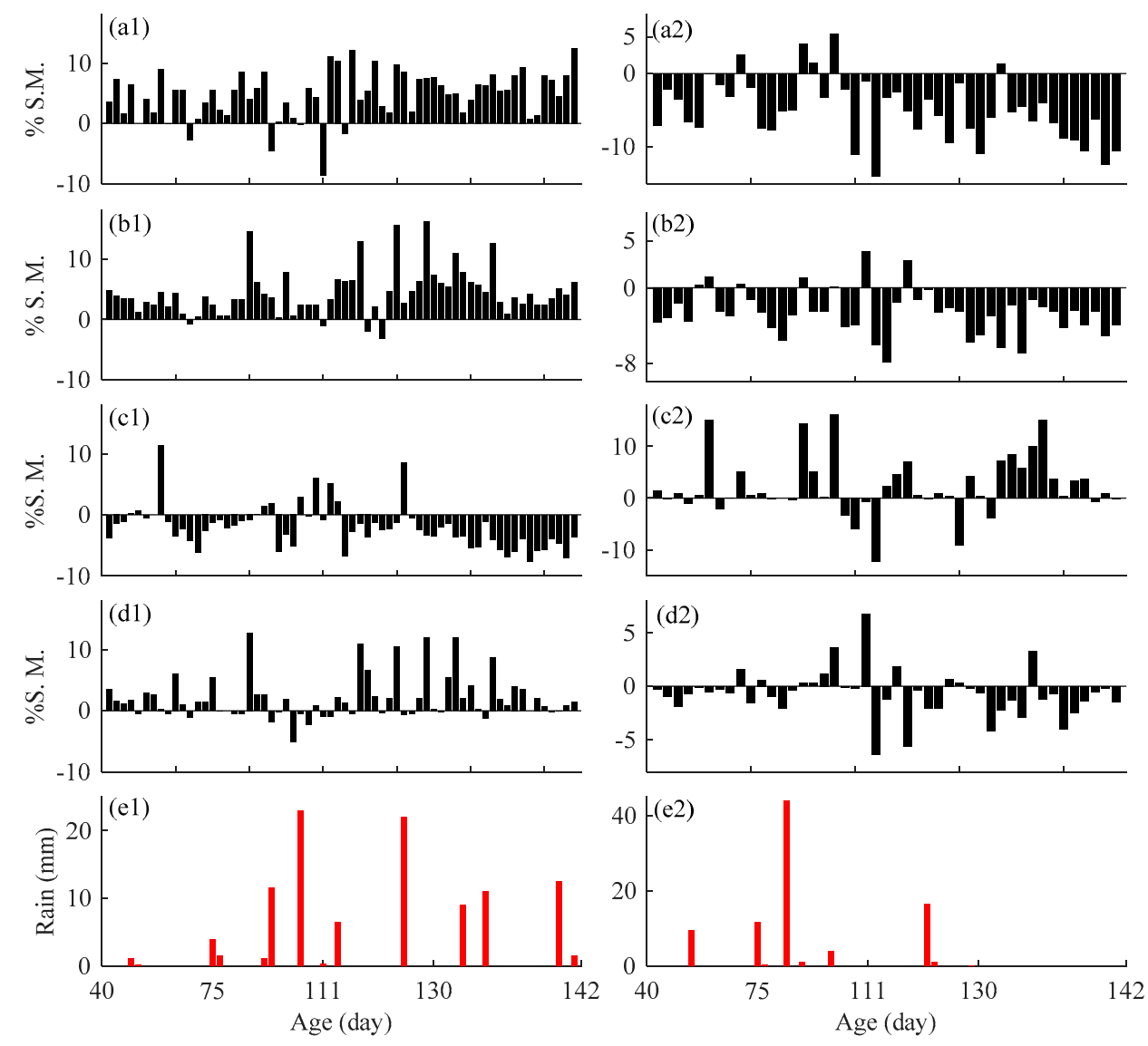

Figure 5. Soil moisture (SM) fluctuations in different treatments during the irrigation period (DIP; $08.00 \mathrm{~h}-16.00 \mathrm{~h}, \mathrm{a} 1, \mathrm{~b} 1, \mathrm{c} 1$ and $\mathrm{d} 1 \mathrm{in} \mathrm{T} 1, \mathrm{~T} 2, \mathrm{~T} 3$ and T4) and outside the irrigation period (OIP; 16.00 h-08.00 h, a2, b2, c2 and d2 in T1, T2, T3 and T4), on day 40-142 of Eucalyptus pellita growth, e1 and e2 timing and magnitude of rainfall events during the DIP and OIP periods.

\subsection{Crop Coefficient, Actual Evapotranspiration, and Potential Evapotranspiration}

Using the weather data collected during the experimental period (Figure 6), daily potential evapotranspiration (ETo) was calculated by the Penman-Monteith method (Figure 7a). Actual evapotranspiration $\left(E T_{0}\right)$ was calculated by solving the water balance equation (Equation (3)) for treatment $\mathrm{T} 1$ in the same period (Figure $7 \mathrm{~b})$. The crop coefficient $\left(\mathrm{K}_{c}\right)$ for E. pellita during initial growth in the open nursery was estimated by applying Equation (1) (Figure 7c). 

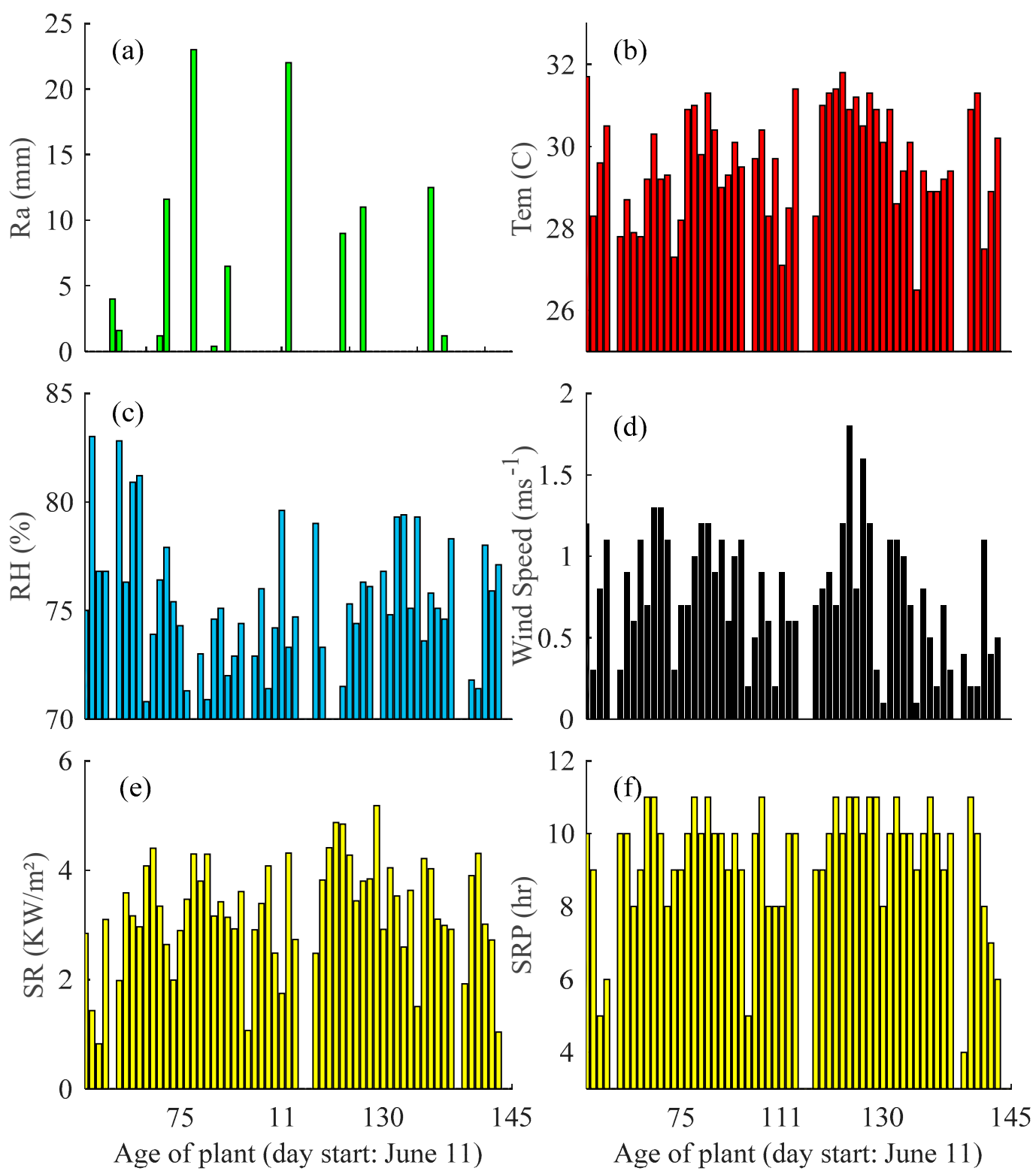

Figure 6. Meteorological data collected by an Automatic Weather Station at the study side during the project period. (a) Rainfall (Ra), (b) temperature (Tem), (c) relative humidity (RH), (d) wind speed, (e) solar radiation (SR), and (f) solar radiation period (SRP). 

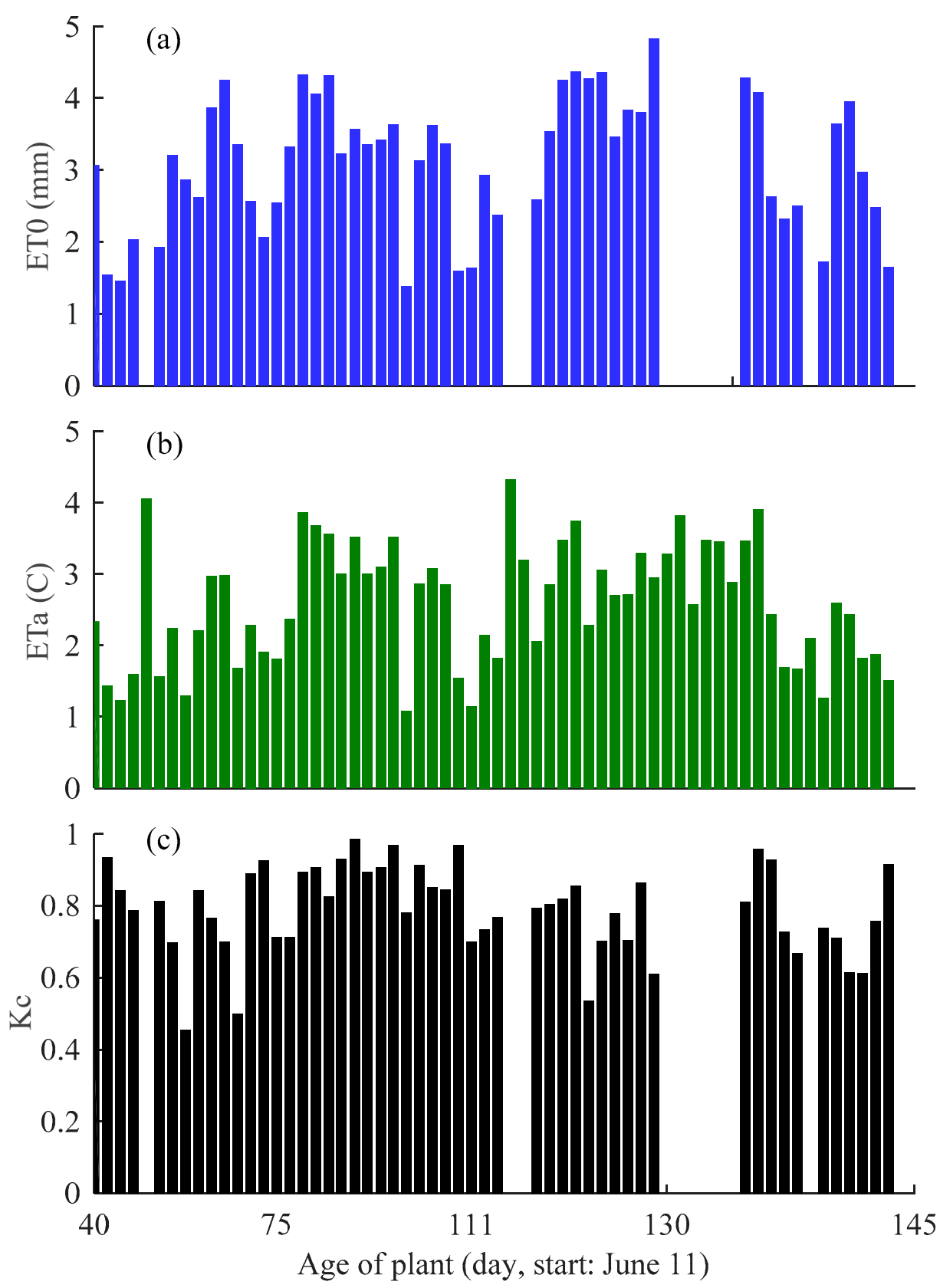

Figure 7. (a) Potential evapotranspiration $\left(\mathrm{ET}_{\mathrm{o}}\right.$, calculated by the Penman-Monteith method), (b) actual evapotranspiration (ETa, calculated from experimental data and water balance) and (c) crop coefficient $\left(\mathrm{K}_{\mathrm{c}}\right)$ during initial growth (days 40-145) of Eucalyptus pellita in an open nursery.

The average $K_{c}$ value was estimated to be 0.79 , with a deviation of \pm 0.12 (Figure $7 \mathrm{c}$ ). For some periods, no $\mathrm{K}_{\mathrm{c}}$ value was obtained, as no ETo value was available. Estimated $\mathrm{K}_{\mathrm{c}}$ for Eucalyptus grandis in the initial growth stage to be 0.70 using the dual crop coefficient method [9], but to our knowledge, our work is the first study to report a $K_{c}$ value for Eucalyptus pellita. The difference in $K_{c}$ value may due to species differences. Another reason can be that calculation of $K_{c}$ and of $\mathrm{ET}_{\mathrm{a}}$ follow the same method and criteria [11], indicating the necessity of determination and/or calibration for local cultivation conditions. As can be clearly seen in Figure 7, ETa and ETo both decreased on day 86 of $E$. pellita growth when there were $22 \mathrm{~mm}$ of rainfall. This means that ETo and $\mathrm{ET}_{\mathrm{a}}$ had a strong correlation, as can also be seen from the coefficient $(R=0.86)$ (Table 1$)$.

The weighing lysimeter generated an error throughout the experiment process. Based on [12], the root mean square error (RMSE), which quantifies how closely two independent datasets match, 
was used to compare the daily values of ETa derived from measurements and daily values of ETo derived from AWS data (Penman-Monteith method). The RMSE value was found to be $0.82 \mathrm{~mm}$ per day $\left(R^{2}=0.76\right)$.

The ETo values calculated based on the Penman-Monteith method showed a strong relationship with air temperature, relative humidity, solar radiation, and net radiation $(\mathrm{R}>0.5)$, while $\mathrm{ET}_{\mathrm{a}}$ was positively correlated with solar radiation and net duration. [13] Observed an inverse correlation between $\mathrm{ET}_{\mathrm{o}}$ and ETa and concluded that, in conditions with no water restriction, Penman-Monteith $E T_{o}$ is proportional to the availability of solar energy and the radiation balance. They also concluded that $\mathrm{ET}_{\mathrm{a}}$ depends on local meteorological elements, increasing as temperature, wind speed, and incoming solar radiation increase, and as relative air humidity decreases. Similarly, [14] concluded that $\mathrm{ET}_{\mathrm{a}}$ is positively correlated with net radiation, wind velocity, air temperature, and specific humidity. Our results show that water restriction only applied in calculating ETo, and not ETa. [15] Concluded that lysimeter irrigation must exceed $\mathrm{ET}_{\mathrm{o}}$ in order to guarantee the water supply for crop evapotranspiration at the maximum rate, which is required to determine the Kc value. 
Table 1. Correlation coefficient (R) between metrological data and experimental results in treatments T1-T3 for Eucalyptus pellita during initial growth in an open nursery.

\begin{tabular}{|c|c|c|c|c|c|c|c|c|c|c|}
\hline Parameter & $\begin{array}{c}\text { ET } \\
\text { o }\end{array}$ & $\begin{array}{l}\mathrm{ET}_{\mathrm{a}} \\
\text { (T1) }\end{array}$ & $\begin{array}{c}\mathrm{Ea} \\
(\mathrm{T} 2)\end{array}$ & $\begin{array}{c}E_{a} \\
(\mathrm{~T} 3)\end{array}$ & $\begin{array}{l}\text { Rain } \\
\text { (mm) }\end{array}$ & $\begin{array}{c}\text { Air Temperature } \\
\left({ }^{\circ} \mathrm{C}\right)\end{array}$ & $\begin{array}{c}\text { Relative Humidity } \\
(\%)\end{array}$ & $\begin{array}{c}\text { Wind Speed } \\
(\mathrm{m} / \mathrm{s})\end{array}$ & $\begin{array}{c}\text { Solar radiation } \\
\left(W / \mathrm{m}^{2}\right)\end{array}$ & $\begin{array}{c}\text { Solar Radiation Period } \\
\text { (h) }\end{array}$ \\
\hline $\mathrm{ET}_{\mathrm{o}}$ & 1 & 0.86 & -0.17 & 0.06 & 0.29 & 0.59 & -0.52 & 0.43 & 0.92 & 0.75 \\
\hline ETa (T1) & & 1 & -0.16 & 0.04 & 0.01 & 0.47 & -0.37 & 0.31 & 0.67 & 0.65 \\
\hline $\mathrm{Ea}(\mathrm{T} 2)$ & & & 1 & 0.02 & 0.03 & 0.12 & 0.01 & 0.06 & -0.12 & -0.18 \\
\hline $\mathrm{Ea} \mathrm{(T3)}$ & & & & 1 & 0.62 & -0.05 & -0.12 & -0.14 & 0.09 & -0.03 \\
\hline Rain (mm) & & & & & 1 & -0.24 & -0.51 & 0.12 & 0.26 & 0.04 \\
\hline Air temperature $\left({ }^{\circ} \mathrm{C}\right)$ & & & & & & 1 & -0.36 & 0.35 & 0.58 & 0.46 \\
\hline Relative humidity (\%) & & & & & & & 1 & 0.05 & -0.52 & -0.18 \\
\hline Wind speed $(\mathrm{m} / \mathrm{s})$ & & & & & & & & 1 & 0.36 & 0.28 \\
\hline Solar radiation $\left(\mathrm{W} / \mathrm{m}^{2}\right)$ & & & & & & & & & 1 & 0.69 \\
\hline $\begin{array}{l}\text { Solar radiation period } \\
\text { (h) }\end{array}$ & & & & & & & & & & 1 \\
\hline
\end{tabular}

Note: Marked values indicate good correlation $(\mathrm{R}>0.5)[10]$ 


\subsection{Effect of Rainfall and Irrigation Recommendations}

In order to compare the effect of rainfall on soil moisture content, the corresponding data were grouped (Figure 8). Soil moisture before a rainfall event (red line in Figure 8) value was not directly affected by rainfall, since the rainfall events occurred randomly. Since treatments T1, T2 and T4 were irrigated, the soil moisture content before rainfall was relatively constant (above the wilting point). In these cases, the soil moisture content after rain did not change much for any intensity of rainfall, since soil moisture conditions were controlled by irrigation. In treatment T3 (no irrigation), soil moisture content dropped in periods between rainfall events. At the highest rainfall intensity of 22 $\mathrm{mm} /$ day, when the soil moisture content was low (<20\%-vol.) it increased strongly (by $\sim 20 \%$-vol.), whereas when it was already high (38-41\%-vol.), i.e., close to saturation point, there was only a minor increase (Figure 8c).

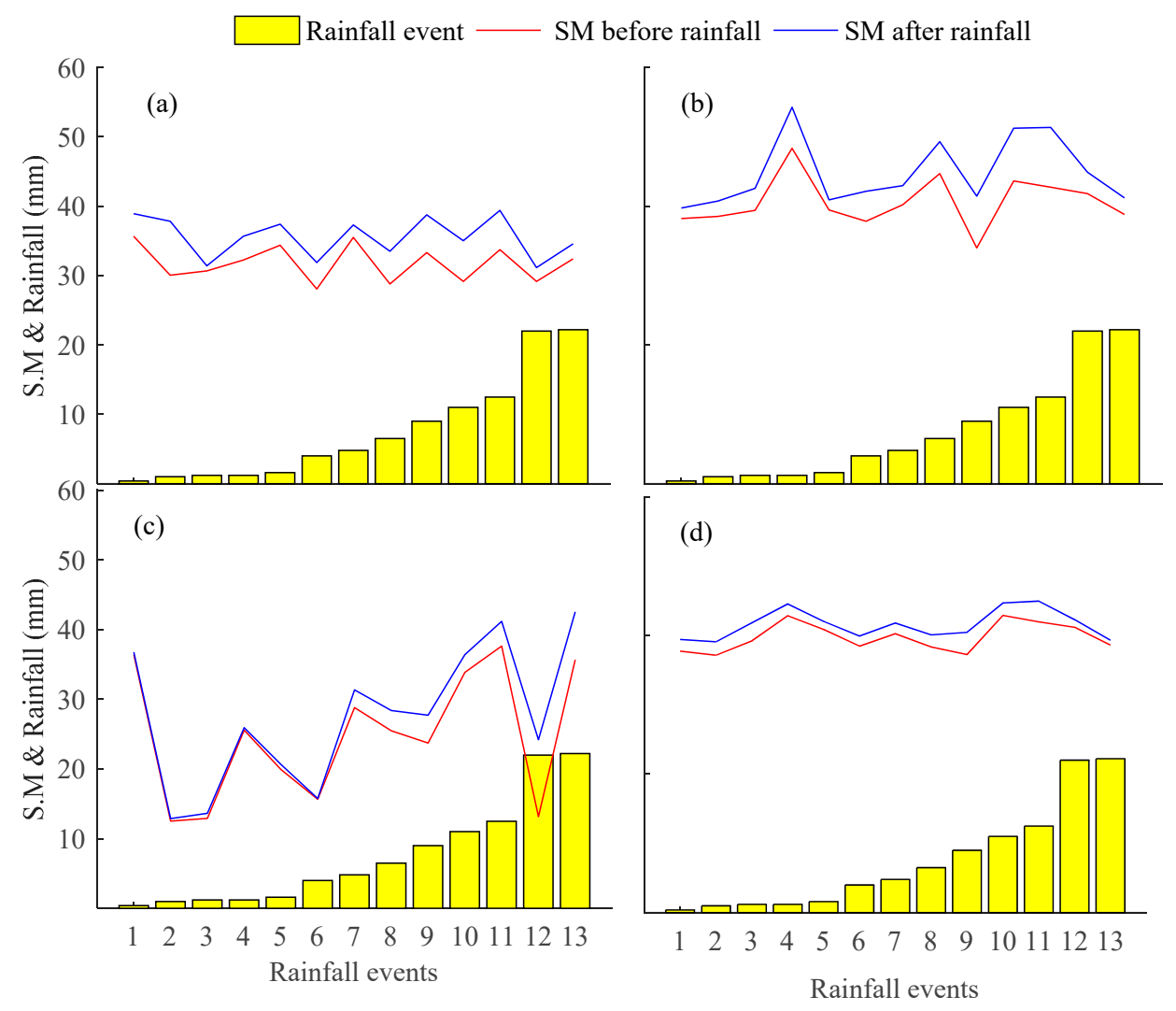

Figure 8. Effect of rainfall events on soil moisture (SM) content in (a-d) treatments T1-T4.

Knowing the value of $K_{c}$, the amount of irrigation required for a specific crop can be defined. In the field, the input of water comes from rainfall, thus, if there is no rainfall, the crop water requirement has to be supplied by irrigation. As irrigation requirements, leaching and percolation also have to be considered [16]. The irrigation requirement of E. pellita during early growth in the nursery (Table 2) was calculated based on rainfall occurrence during the measurement period and assuming leaching of $5 \mathrm{~mL}$ and a soil moisture content of 22\%-vol. (above wilting point). Water wastage (up to $20 \%$ ) occurs if irrigation is based on overestimated $K_{c}$ values [17], while yield reductions (up to $38 \%$ ) occur if irrigation is based on underestimated $K_{c}$ values [18]. It is worth noting that the recommended irrigation requirement of Eucalyptus pellita in this research is related to plants in the nursery stage. After the nursery stage, the plants will be transferred to the field (forestry plantation area) where the irrigation demand is supplied by precipitation. 
Table 2. Irrigation requirement of Eucalyptus pellita during early growth, based on rainfall occurrence.

\begin{tabular}{cc}
\hline Rainfall (mm/day) & Irrigation Per plant Per Day $(\mathbf{m L})$ \\
\hline $0-9$ & 70 \\
$9-19$ & 50 \\
$19-30$ & 30 \\
$>30$ & 0 \\
\hline
\end{tabular}

\section{Conclusions}

The experimental lysimeter set-up used in this study enabled a good understanding of water balance components for Eucalyptus pellita. During the dry season, rainfall in the study region is limited and the soil moisture content decreases over time, thus, irrigation is essential in order to keep the level above wilting point.

Actual evapotranspiration (ETa) and potential (reference) evapotranspiration $\left(E T_{0}\right)$ showed a good correlation $(\mathrm{R}=0.86)$. Calculating their ratio resulted in a crop coefficient $\left(\mathrm{K}_{\mathrm{c}}\right)$ value for E. pellita of $0.79( \pm 0.12)$ during the initial growth stage (40-142 days), compared with a $K_{\mathrm{c}}$ value for Eucalyptus grandis of 0.70 . ETo showed a strong positive correlation $(\mathrm{R}>0.5)$ with temperature, relative humidity, solar radiation, and radiation period.

In the absence of irrigation, if the soil moisture content is below wilting point a rainfall event supplying $22 \mathrm{~mm}$ /day will increase the moisture content by about $20 \%$-vol., but if the soil is already close to saturation, it will cause no major change in soil moisture. The irrigation recommendation in the field varies depending on precipitation, from $70 \mathrm{~mL} /$ plant/day in the case of no rainfall to zero with rainfall above $30 \mathrm{~mm} /$ day. Further studies may be required to confirm this recommendation.

Author Contributions: conceptualization, D.A., B.k, and A.T.H.; methodology, D.A., B.K. and A.T.H.; software, D.A., M.I.H. and A.T.H.; validation, D.A., M.I.H. and A.T.H.; formal analysis, D.A., M.I.H., and A.T.H.; investigation, D.A., M.I.H. and A.T.H.; resources, D.A. and M.I.H.; data curation, D.A., M.I.H. and A.T.H.; writing-original draft preparation, D.A.; writing-review and editing, D.A., B.K. and A.T.H.; visualization, D.A., and A.T.H.; supervision, B.K. and A.T.H.; project administration, M.I.H.; funding acquisition, B.K.

Funding: This research was funded by Sinarmas Forestry Company and Doctoral Degree Program at University Oulu.

Acknowledgments: The author would like to thank Gurdeep D. Golani as Dy CEO of Sinarmas Forestry for providing support so the author can join in Doctoral Degree Program. The study was financially supported by PT. Arara Abadi (Sinarmas Forestry) and scientifically supported by the Doctoral Degree Program at the Water, Energy and Environmental Engineering Research Unit, University of Oulu, Finland.

Conflicts of Interest: The authors declare no conflict of interest.

\section{References}

1. Bristow, M. Growth of Eucalyptus Pellita in Mixed Species and Monoculture Plantations. Ph.D. Thesis, Southern Cross University, Lismore, Australia, 2008.

2. Lukmandaru, G.; Zumaini, U.F.; Soeprijadi, D.; Nugroho, W.D.; Susanto, M. Chemical Properties and Fiber Dimension of Eucalyptus pellita from the 2nd Generation of Progeny Tests in Pelaihari, South Borneo, Indonesia. Korean Wood Sci. Technol. 2016, 44, 571-588.

3. Setyaji, T.; Sunarti, S.; Nirsatmanto, A. Early growth and stand volume productivity of selected clones of Eucalyptus pellita. Indones. J. For. Res. 2016, 3, 27-32.

4. Yuniarti, K.; Nirsatmanto, A. Several physical properties of Eucalyptus pellita F. Muell from different provenances and sampling position on tree. J. Peneli. Kehutan. Wallace 2018, 7, 151-163.

5. Hardie, M.; Mendham, D.; Corkrey, R.; Hardiyanto, E.; Maydra, A.; Siregar, S.; Marolop, R.; Wibowo, A. Effects of Eucalypt and Acacia plantations on soil water in Sumatra. New Forests 2018, 49, 87-104.

6. Kunert, N.; Cárdenas, A. Are mixed tropical tree plantations more resistant to drought than monocultures? Forests 2015, 6, 2029-2046.

7. Da Silva V.D.P.; da Silva, B.B.; Albuquerque, W.G.; Borges, C.J.; de Sousa, I.F.; Neto, J.D. Crop coefficient, water requirements, yield and water use efficiency of sugarcane growth in Brazil. Agric Water Manag. 2013, $128,102-109$. 
8. Schrader, F.; Durner, W.; Fank, J.; Gebler, S.; Pütz, T.; Hannes, M.; Wollschläger, U. Estimating precipitation and actual evapotranspiration from precision lysimeter measurements. Procedia Environ. Sci. 2013, 19, 543552.

9. Alves, M.E.B.; Mantovani, E.C.; Sediyama, G.C.; Neves, J.C.L. Estimate of the crop coefficient for Eucalyptus cultivated under irrigation during initial growth. Cerne 2013, 19, 247-253.

10. Kotrlik, J.W.; Williams, H.A.; Jabor, M.K. Reporting and Interpreting Effect Size in Quantitative. Agric. Educ. 2011, 52, 132-142.

11. de Carvalho, D.F.; de Lima, M.E.; de Oliveira, A.D.; da Rocha, H.S.; Guerra, J.G. Crop coefficient and water consumption of eggplant in no-tillage system and conventional soil preparation. Eng. Agric. 2012, 32, 784793.

12. Kashyap, P.S.; Panda, R.K. Evaluation of evapotranspiration estimation methods and development of cropcoefficients for potato crop in a sub-humid region. Agric. Water Manag. 2001, 50, 9-25.

13. Monteiro, E.B.; da Silva, A.C.; Souza, A.P.; Tanaka, A.A.; Ferneda, B.G.; Martim, C.C. Water requirements and crop coefficients of tropical forest seedlings in different shading conditions. Revista Brasileira de Engenharia Agricola e Ambiental 2016, 20, 709-715.

14. Gu, L.; Hu, Z.; Yao, J.; Sun G. Actual and reference evapotranspiration in a cornfield in the zhangye oasis, northwestern China. Water 2017, 9, 499.

15. Libardi, L.G.P.; de Faria, R.T.; Dalri, A.B.; de Souza Rolim, G.; Palaretti, L.F.; Coelho, A.P.; Martins, I.P. Evapotranspiration and crop coefficient $(\mathrm{Kc})$ of pre-sprouted sugarcane plantlets for greenhouse irrigation management. Agric. Water Manag. 2019, 212, 306-316.

16. Savva, A.P.; Frenken, K. Irrigation Manual: Planning, Development Monitoring and Evaluation of Irrigated Agriculture with Farmer Participation; FAO: Rome, Italy, 2002; Volume IV.

17. Djaman, K.; O’Neill, M.; Owen, C.; Smeal, D.; Koudahe, K.; West, M.; Allen, S.; Lombard, K.; Irmak, S. Crop evapotranspiration, irrigation water requirement and water productivity of maize from meteorological data under semiarid climate. Water 2018, 10, 405.

18. Kharrou, M.H.; Er-Raki, S.; Chehbouni, A.; Duchemin, B.; Simonneaux, V.; LePage, M.; Ouzine, L.; Jarlan, L. Water use efficiency and yield of winter wheat under different irrigation regimes in a semi-arid region. Agric. Sci. 2011, 2, 273-282. 